
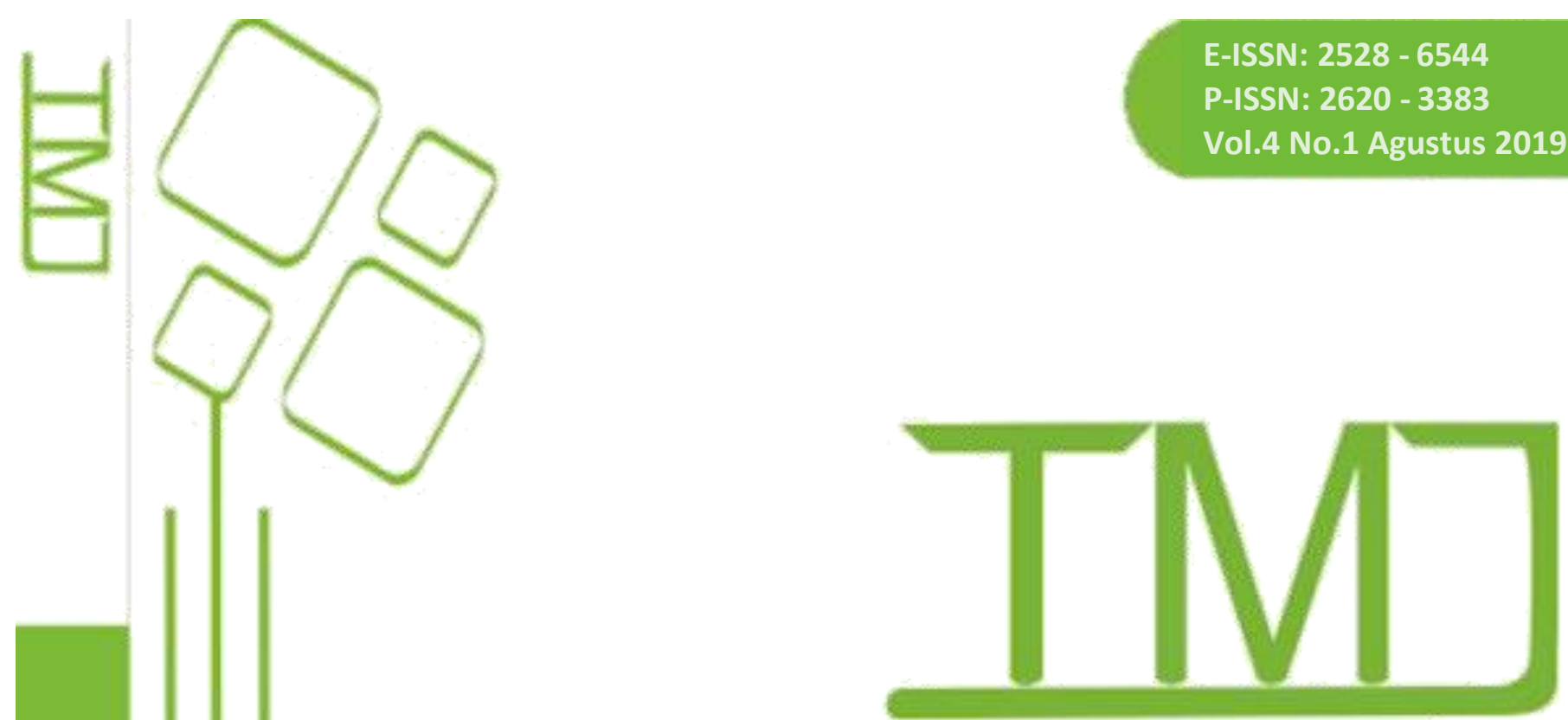

\title{
Technomedia Joutnal
}

\section{iLearning Journal Center (iJC)}

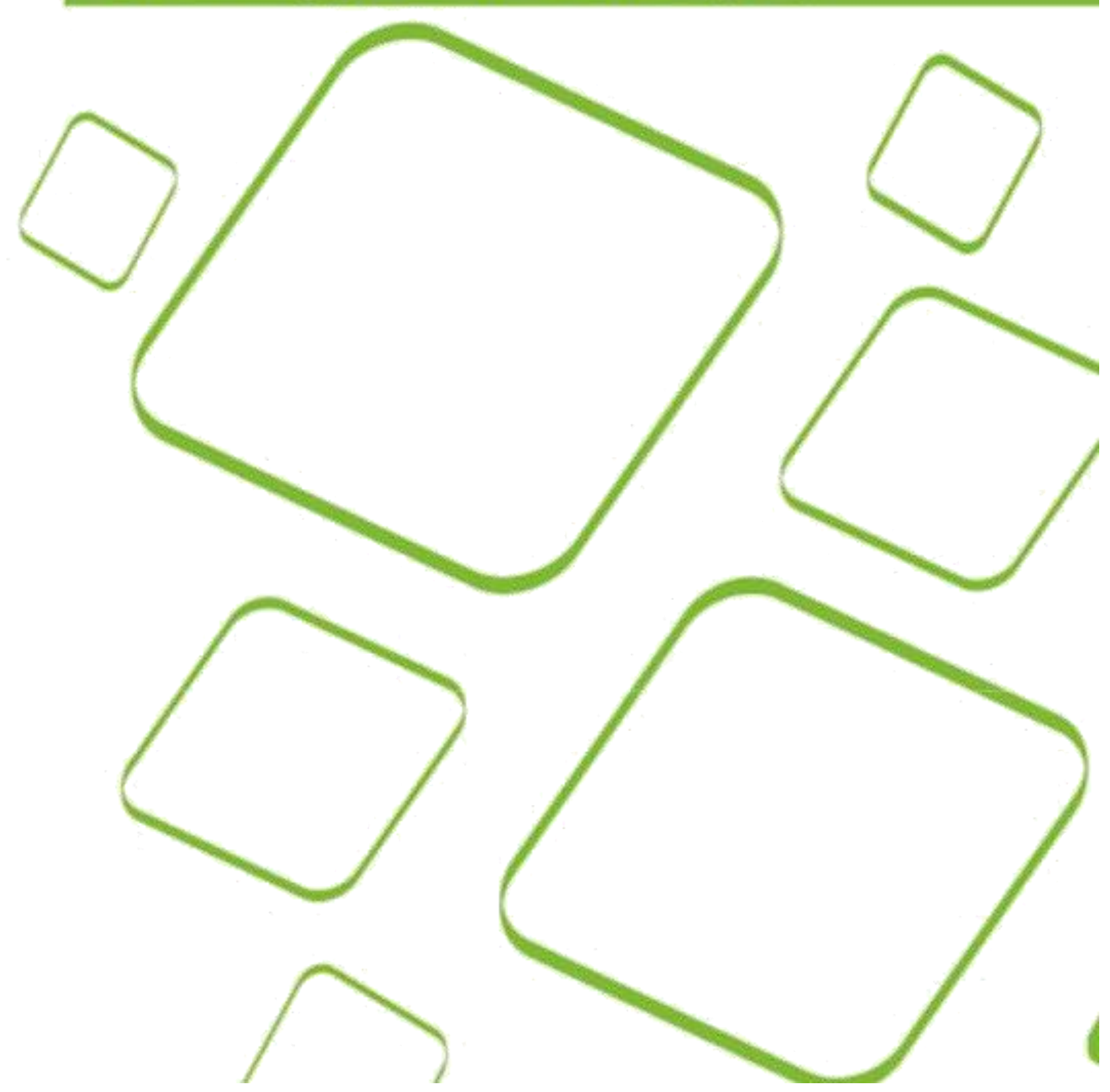




\title{
Alat Pengukur Ketinggian Air Berbasis Microcontroller Sebagai Peringatan Banjir Dengan Notification
}

\author{
Indri Handayani ${ }^{1}$ \\ Ade Setiadi ${ }^{2}$ \\ Fajar Nur Iman ${ }^{3}$ \\ Dosen Universitas Raharja ${ }^{l},{ }^{2}$ \\ Mahasiswa Jurusan Sistem Komputer Universitas Raharja ${ }^{3}$ \\ E-mail : indri@raharja.info ${ }^{1}$, adesetiadi@raharja.info ${ }^{2}$,fajar.nur@raharja.info ${ }^{3}$
}

\begin{abstract}
ABSTRAK
Sensor Ultrasonic adalah suatu perangkat yang sering digunakan pada perusahaan industri. Sensor Ultrasonic memiliki fungsi sebagai pendeteksi dan pengukur jarak.cara kerja sensor ultrasonic adalah sensor akan memancarkan gelombang ultrasonic pada permukaan lalu menangkapnya kembali, sehingga hasil yang didapat sesuai dengan keadaan aslinya. Beberapa perusahaan mobil menggunakan sensor ultrasonic ini pada mobil sebagai alat untuk mengukur jarak agar tidak tabrakan dengan kendaraan lain. Sensor ini sangat cocok digunakan untuk merancang sebuah alat pengukur ketinggian air, karena selain efektif sensor ini juga memberikan hasil yang akurat. Dari beberapa percobaan yang dilakukan, dihasilkan bahwa sensor ultrasonic cukup efektif dalam pengukuran pada jarak $1 \mathrm{~cm}-300 \mathrm{~cm}$. dari perancangan alat pengukur ketinggian air berbasis sensor ultrasonic ini hasil yang didapat akan ditampilkan pada layar lcd $16 x 2 \mathrm{~cm}$ sebagai pemberi informasi dan beberapa lampu led untuk memberikan batasan-batasan dari ketinggian tersebut serta buzzer sebagai tanda peringatan bahwa ketinggian air maksimal.
\end{abstract}

Kata kunci: sensor ultrasonic, pengukur ketinggian air, Arduino

\begin{abstract}
Ultrasonic sensor is a device that is often used in industrial companies. Ultrasonic sensor has a function as a detector and distance measuring. Ultrasonic sensor work is the sensor will emit ultrasonic waves on the surface and then catch it back, so the results obtained in accordance with the original state. Some car companies use this ultrasonic sensor on the car as a means to measure the distance so as not to collide with other vehicles. This sensor is very suitable for designing a water level gauge, because in addition to effective sensors also provide accurate results. From several experiments conducted, it was generated that ultrasonic sensors were quite effective in measuring at a distance of $1 \mathrm{~cm}-300 \mathrm{~cm}$. from the design of ultrasonic sensorbased water meter this results obtained will be displayed on the $16 \times 2 \mathrm{~cm}$ lcd screen as a giver of information and some led lights to provide restrictions of the height and buzzer as a warning sign that the maximum water level.
\end{abstract}

Keywords: ultrasonic sensor, water level meter, arduino 


\section{PENDAHULUAN}

Kemajuan ilmu teknologi saat ini sangat berkembang pesat, manusia terus mengembangkan teknologi guna untuk mempermudah pekerjaan terutama pekerjaan yang sifatnya berulang-ulang. sangat tidak efisien jika pekerjaan tersebut dilakukan dengan cara manual, maka dari itu diciptakanlah alat-alat industri yang mempermudah pekerjaan yang berulang terus menerus. salah satu dari banyaknya teknologi yang sedang berkembang adalah microcontroller dan sistem sensor. microcontroller sendiri adalah sebuah perangkat yang didalamnya tertanam sebuah chip bernama mikroprosesor berfungsi untuk memproses data secara digital sesuai dengan perintah yang diinstruksikan. Sedangkan sistem sensor adalah perangkat berupa alat yang diciptakan untuk mengidentifikasi sebuah objek dan mendeteksi adanya perubahan lingkungan fisik maupun kimia.

Dengan berkembangnya microcontroller dan sensor, manusia menciptakan alat yang berhubungan dengan kehidupan sehari-hari dan dapat diaplikasikan. muncul berbagai macam alat-alat yang menarik yang sangat membantu dan mempermudah kehidupan manusia, Dengan diciptakannya mikroprosesor, manusia dapat membuat dan memodifikasi sistem teknologi sesuai dengan keinginan atau yang dibutuhkannya sendiri. Salah satu contoh microcontroller yang sering digunakan dan mudah didapat adalah Arduino Uno. Jenis microcontroller ini merupakan jenis perangkat pengolahan data yang sering digunakan dan sangat populer digunakan. Perangkat ini menggunakan bahasa $\mathrm{C}$ yang mudah untuk dimengerti dan memiliki banyak fungsi.

Suatu wadah atau tangki tempat air terkadang kita tidak tahu apakah tinggal sedikit atau banyak. Dan juga ketika sedang mengisi air terkadang lupa kalau airnya sudah penuh sehingga kita membuang air yang tidak sedikit. Tujuan menciptakan perancangan alat pengukur ketinggian air ini adalah untuk diimplementasikan pada suatu wadah air atau di sungai sebagai peringatan bahwa ketinggian air maksimal atau sebagai peringatan dini banjir. Sistem yang berbasis microcontroller ini dapat dijadikan sebagai suatu alternatif karena memiliki kemampuan yang diperlukan oleh sebuah sistem yang rumit. Sehingga sistem berbasis microcontroller merupakan sistem yang memiliki efisiensi dan efektivitas yang tinggi.

\section{PERMASALAHAN}

Banjir merupakan hal yang biasa bagi warga indonesia, terutama di daerah yang padat penduduk. kurang disiplinnya masyarakat yang kebiasaan membuang sampah sembarangan, terutama di sungai atau kali sebagai aliran air, karena sampah menumpuk sehingga membuat aliran air tersumbat dan terjadilah banjir. meskipun indonesia sudah biasa menghadapi banjir, tetapi masih banyak orang yang tidak mempersiapkan diri sebelum terjadinya banjir, sehingga banyak barang-barang yang hanyut terbawa banjir. 


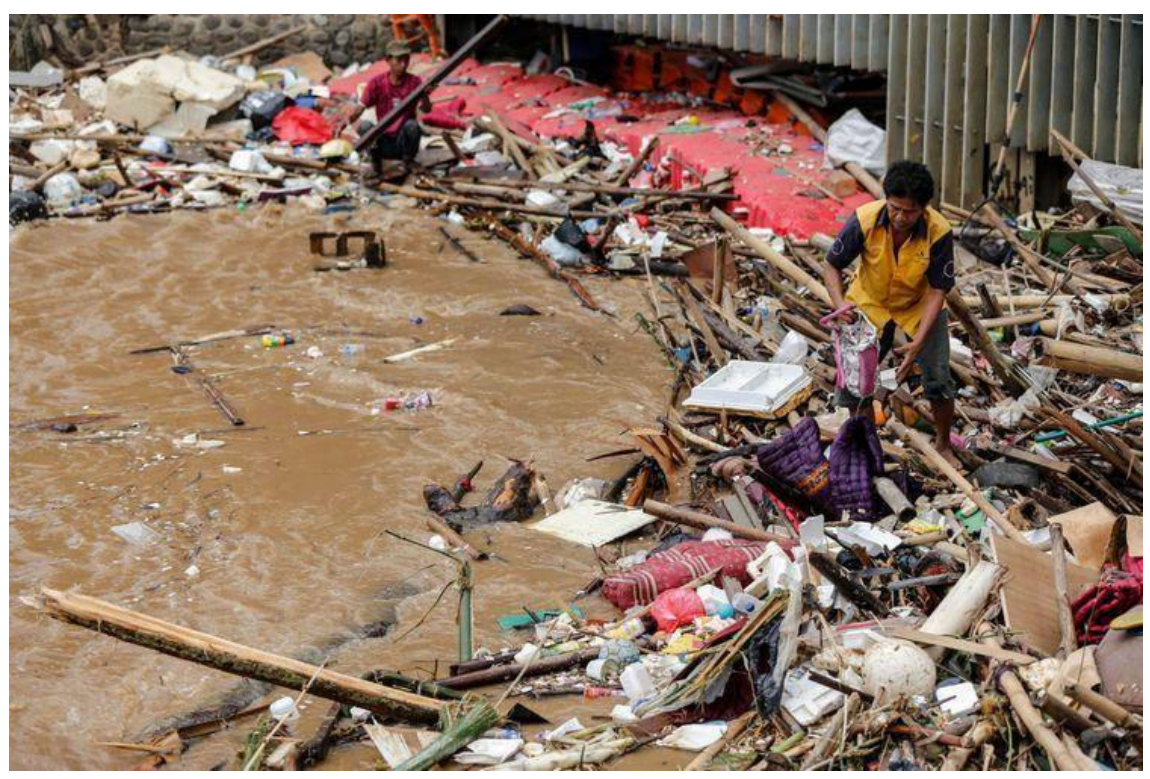

Gambar 1. Banjir

(Sumber : https://megapolitan.kompas.com)

Dengan diciptakannya alat mengukur ketinggian air ini masyarakat akan mendapatkan informasi atau notification berupa sms yang menginformasikan ketinggian air, sehingga masyarakat dapat mempersiapkan diri menghadapi banjir dan barang-barang dapat diamankan terlebih dahulu.

\section{METODE PENELITIAN}

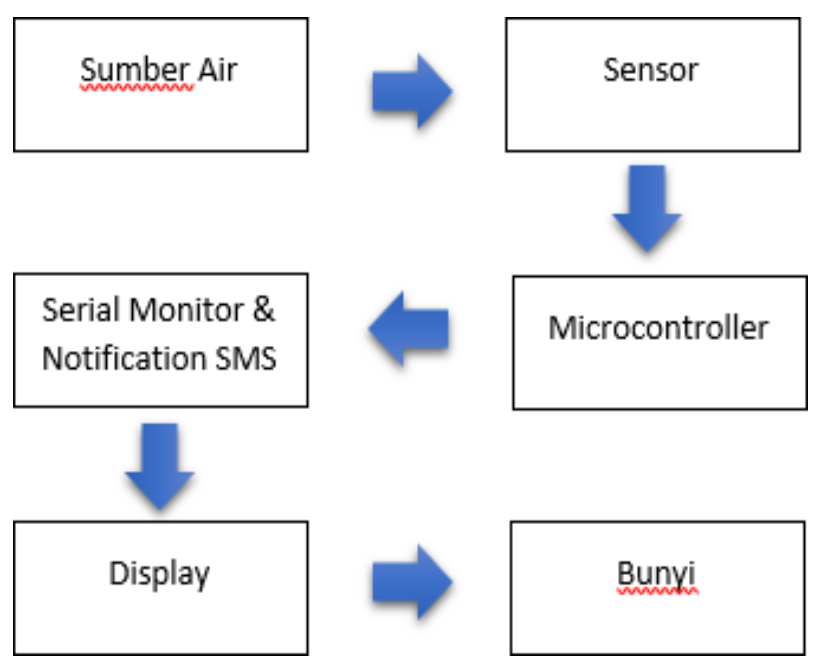

Gambar 2. Blok diagram system 


\section{a. Sumber Air}

Sumber air yang digunakan dapat berupa sungai atau kali yang ketinggiannya berubahubah untuk memantau ketinggian dan kerja sensor, pada pengujian ini sumber air disimpan pada wadah khusus dan dikeluarkan pada saat pengujian.

\section{b. Sensor}

Untuk mendeteksi ketinggian air dalam suatu tangki, pada sistem ini digunakan sensor ultrasonic. Sensor dapat dipasang diatas tangki dan memancarkan gelombang ultrasonic ke permukaan air. Sensor ini menggunakan prinsip pantulan gelombang ultrasonic. Ketika gelombang ultrasonic dipancarkan oleh sensor ini dan terdapat objek yang menyebabkan gelombang tersebut terpantul, maka sensor tersebut akan memberikan data ke microcontroller. Sensor ultrasonic berperan sebagai input.
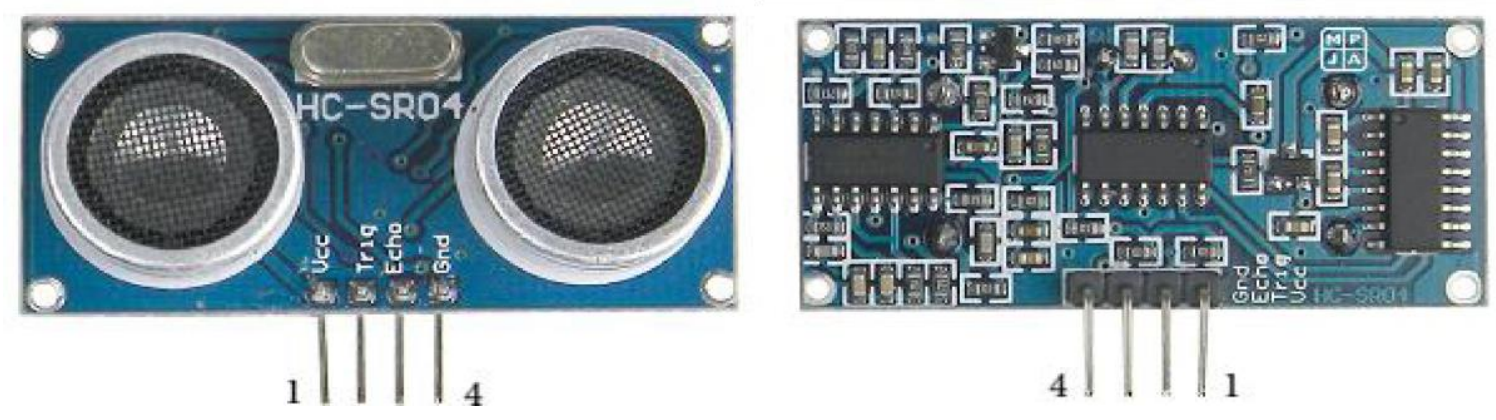

Gambar 3. Sensor ultrasonic HC-SR04: tampak depan (kiri), tampak belakang (kanan)

(Sumber : https://depokinstruments.com)

\section{c. Microcontroller}

Microcontroller merupakan sebuah perangkat keras yang didalamnya tertanam chip mikroprosesor berfungsi untuk memproses sebuah data atau informasi yang akan dikirimkan ke user. Ada berbagai macam microcontroller yaitu Arduino uno, Arduino mega, Arduino nano, dll.

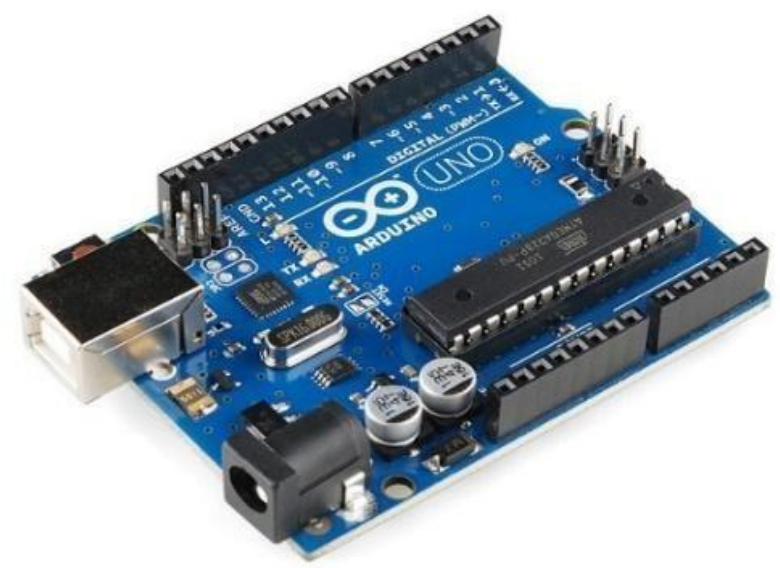

Gambar 4. Arduino uno

(Sumber : https://www.arduino.cc/) 
saya menggunakan Arduino uno karena beberapa hal yaitu fiturnya cukup lengkap dan banyak referensi, tidak terlalu besar jika dibandingkan dengan Arduino mega, dan cocok untuk dikembangkan. Microcontroller berperan sebagai pemroses, dan akan mengirimkan sebuah instruksi kepada output.

\section{d. Serial monitor \& Notification SMS}

Serial monitor berupa sebuah pesan yang ditampilkan atau notification yang dikirimkan oleh microcontroller dan diterima oleh user. Untuk bisa mendapatkan sebuah notification berupa SMS, maka system memerlukan sebuah perangkat pengirim notification yaitu module GSM. Modul GSM adalah sebuah perangkat yang memiliki port sim card, yang berfungsi untuk menghubungkan Arduino dengan GSM.

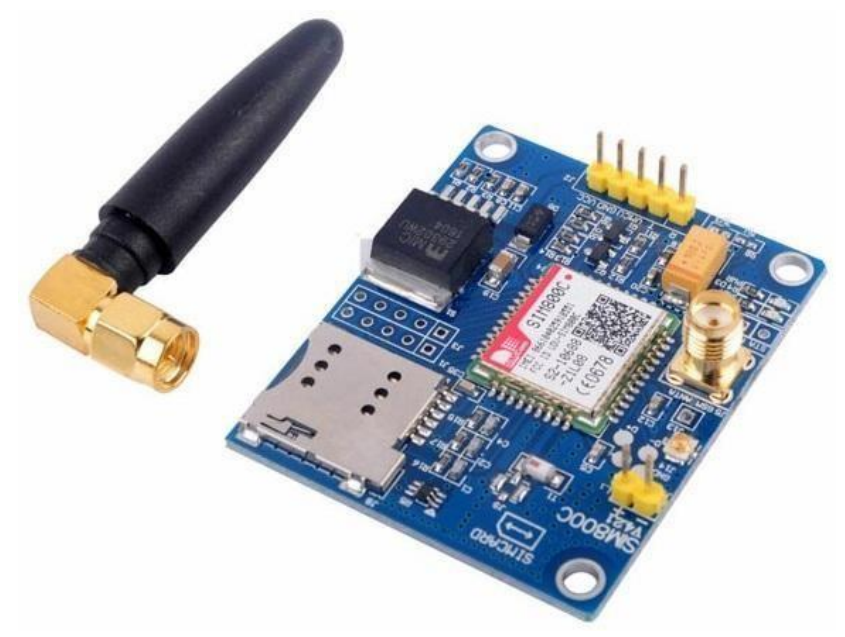

Gambar 5. Module GSM

(Sumber : http://spectrumes.com)

Dengan module ini kita dapat menjadikannya sebagai pengontrol lewat ponsel atau sebagai pemberi notifikasi yang dikirimkan lewat sms.

\section{e. Display}

LCD (Liquid Crystal Display) adalah suatu jenis media tampilan yang menggunakan kristal cair sebagai penampil utama. LCD dapat menampilkan gambar dan tulisan karena terdapat banyak sekali titik cahaya yang terdiri dari satu buah Kristal. Walau disebut sebagai titik cahaya, namun kristal cair ini tidak memancarkan cahaya sendiri. Sumber cahaya di dalam sebuah perangkat LCD adalah lampu neon berwarna putih di bagian belakang susunan kristal cair tadi. 


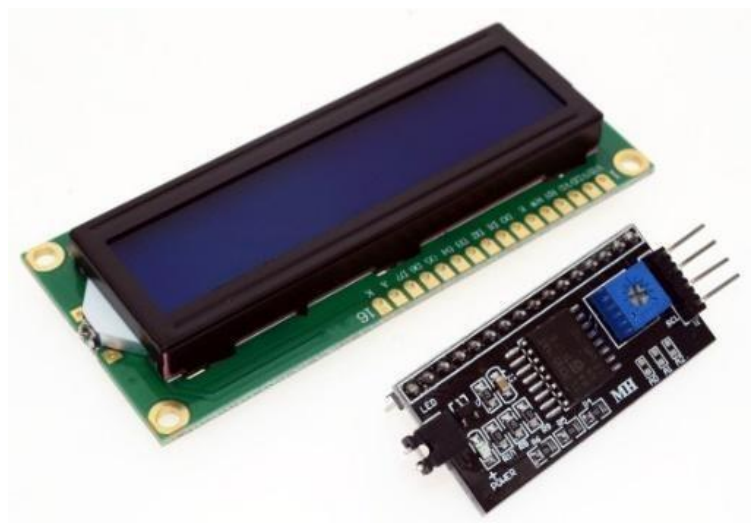

Gambar 6. LCD \& IIC

(Sumber : http://troncart.com)

Meskipun LCD bisa digunakan secara langsung tetapi ada IC yang digabungkan dengan LCD agar lebih mudah mengoperasikannya yaitu IIC/I2C (Inter Integrated Circuit) guna menggabungkan 16 pin pada LCD menjadi 4 pin. LCD berperan sebagai output menampilkan pesan kepada user.

\section{f. Bunyi}

Banyak perangkat yang dapat digunakan dan dimanfaatkan sebagai output sebuah suara, salah satunya adalah buzzer. buzzer adalah sebuah perangkat elektronik yang berfungsi sebagai pengubah getaran listrik menjadi getaran suara. buzzer terdiri atas kumparan yang terdapat pada diafragma dan kemudian kumparan tersebut dialiri arus listrik sehingga menjadi elektromagnet. Kumparan tersebut kemudian tertarik kedalam dan keluar secara bolak-balik tergantung pada arus yang mengalirinya sehingga membuat udara bergetar dan menghasilkan sebuah suara.

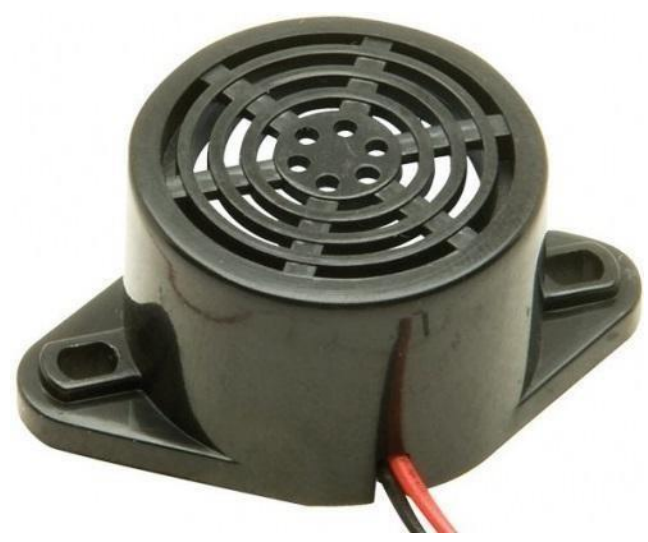

Gambar 7. Buzzer (Speaker)

(Sumber : http://www.hobbytronics.co.uk)

Buzzer biasa digunakan sebagai indikator bahwa proses telah selesai atau terjadi suatu kesalahan pada sebuah alat (alarm).buzzer berperan sebagai output yang berbunyi ketikan ketinggian air telah maksimal. 
Penelitian yang perlu dilakukan studi pustaka sebagai salah satu dari penerapan metode penelitian yang perlu untuk dilakukan. Diantaranya adalah mengetahui orang lain yang spesialisasi dan area penelitian yang sama di bidang ini. Beberapa literature review tersebut adalah sebagai berikut :

1. Penelitian yang dilakukan oleh Dwiyatno \& Prabowo (2017) yang berjudul "Rancang Bangun Alat Ukur Tinggi Badan Digital Menggunakan Sensor Ultrasonik" menjelaskan penggunaan arduino uno sebagai microcontroller dan sensor ultrasonic sebagai pengukur tinggi badan memberikan hasil yang akurat, dan tentu saja dapat membantu pekerjaan puskesmas lebih cepat dan efisiensi. metode penelitian yang digunakan adalah Penelitian Lapangan (Field Research), Penelitian Kepustakaan (Library Research) dan Observasi. Teknik analisa data dalam pembuatan perangkat lunak menggunakan paradigma perangkat lunak secara waterfall.

2. Penelitian yang dilakukan oleh Susanto, Kristanto, Ridwanto, \& Hisnuaji (2007) dengan judul "Perancangan Dan Implementasi Sensor Parkir Pada Mobil Menggunakan Sensor Ultrasonik." menjelaskan bahwa penggunaan sensor ultrasonic untuk mendeteksi posisi belakang mobil saat parkir dapat bermanfaat dan berfungsi dengan baik, sehingga meskipun jangkauan pandangan kita terbatas, tetap bisa memarkirkan mobil dengan lebih mudah. serta berpendapat bahwa Sensor ultrasonik adalah salah satu sensor yang paling akurat diantara beberapa sensor yang digunakan untuk mengukur jarak. Metode penelitian yang digunakan adalah penelitian lapangan dan pengumpulan data.

3. Penelitian yang dilakukan oleh Wiharto, Lyndia, Holy; Yuliananda (2016) yang berjudul "Penerapan Sensor Ultrasonik Pada Sistem Pengisian Zat Cair Dalam Tabung Silinder Berbasis Mikrokontroler ATmega 16."menjelaskan bahwa sensor ultrasonic dan microcontroller ATmega sebagai alat pengukur ketinggian pada pengisian zat cair dalam tabung silinder memberikan hasil yang akurat dan setelah ketinggian air mencapai $17 \mathrm{~cm}$, maka air berhenti mengisi. serta berpendapat Sensor ultrasonik adalah transduser yang mengubah waktu rambat gelombang ultrasonik menjadi jarak tempuh galombang melalui konversi banyaknya pulsa yang diterima per detik, sehingga sensor ultrasonik dapat mengukur jarak objek.

4. Penelitian yang dilakukan oleh Suhaeb (2016) dengan judul "Desain Tongkat Elektronik Bagi Tunanetra Berbasis Sensor Ultrasonik Dan Mikrokontroler Atmega8535." menjelaskan bahwa tongkat elektronik yang digunakan untuk mendeteksi benda yang berada di depannya, dapat memberikan informasi pada para tunanetra. Dan Dari hasil pengujian dapat disimpulkan bahwa tongkat elektronik tunanetra ini cukup memuaskan, karena hasil respon pengujian perbandingan tongkat elektronik dengan tongkat tunanetra yang dinilai dari aspek keefektifan, kemudahan, keamanan, dan keunggulan. Penelitian ini menggunakan metode rekayasa yang sifatnya rancang produk atau pengamatan secara langsung, yaitu pengamatan terhadap cara kerja mikrokontroler sebagai perangkat proses dengan aplikasi beberapa perangkat input dan output.

5. Penelitian yang dilakukan oleh Budiarso \& Prihandono (2015) yang berjudul "Implementasi Sensor Ultrasonik Untuk Mengukur Panjang Gelombang Suara Berbasis Mikrokontroler" berpendapat bahwa Pengukur jarak dengan sensor ultrasound merupakan salah satu sensor yang dapat digunakan untuk menentukan jarak suatu benda yang berada di suatu tempat dengan benda lain yang berada di tempat yang 
berbeda. Aplikasi dari sensor ultrasound diantaranya adalah untuk menentukan ketinggian air bendungan, sistem kendali robot, dan lain-lain. Penelitian ini menggunakan metode rekayasa yang sifatnya rancang produk atau pengamatan secara langsung, yaitu pengamatan terhadap cara kerja mikrokontroler sebagai perangkat proses dengan aplikasi beberapa perangkat input dan output.

6. Penelitian yang dilakukan oleh Arasada, Bakhtiyar, \& Suprianto (2017) dengan judul "Aplikasi Sensor Ultrasonik Untuk Deteksi Posisi Jarak Pada Ruang Menggunakan Arduino Uno." berpendapat bahwa Sensor ultrasonik adalah sensor yang memanfaatkan prinsip gelombang ultrasonic, Gelombang ultrasonik merupakan gelombang akustik yang memiliki frekuensi mulai $20 \mathrm{kHz}$ hingga sekitar $20 \mathrm{MHz}$ (Arief, 2011). Sensor ultrasonik biasanya digunakan untuk mengukur jarak suatu benda yang berada di hadapan sensor tersebut, adapun beberapa aplikasi dari sensor tersebut adalah sebagai pengukur level ketinggian dan volume air.

Dari pengertian dan pendapat diatas, maka dapat disimpulkan bahwa sensor ultrasonic sangatlah cocok dan memiliki banyak kelebihan dibandingkan dengan sensor pengukur jarak lainnya, selain itu pengguna nya juga sangat efisien dan akurat mengukur jarak dari $2 \mathrm{~cm}-300$ $\mathrm{cm}$, serta mudah diaplikasikan dan referensinya sangat luas.

\section{HASIL PEMBAHASAN \\ Perancangan Sistem}

Perancangan sistem ini dibagi menjadi 3 tahapan, tahapan pertama yaitu perancangan model yang berhubungan dengan kebutuhan perangkat keras dan perangkat lunak. tahapan kedua yaitu perancangan algoritma untuk memberikan alur program dan pemecahan masalah pada sistem, pemecahan masalah harus diselesaikan dengan cara terperinci. tahapan ketiga yaitu pengujian pada sistem, dengan mencoba keseluruhan kemungkinan hal yang terjadi pada sistem.

\section{A. Perangkat keras}

Perancangan sistem merupakan salah satu hal yang harus dilakukan pada saat membangun sebuah sistem. 


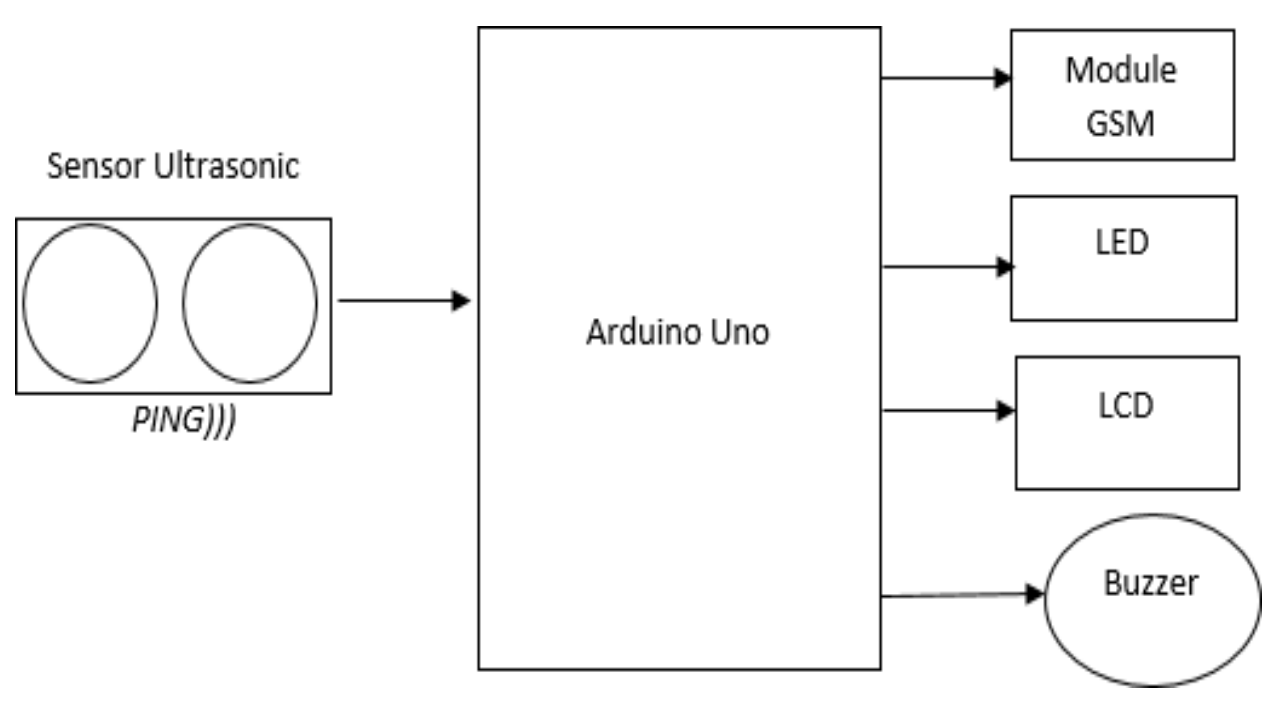

Gambar 8. Diagram Blok

Perancangan perangkat keras dalam sistem ini terdiri dari beberapa modul. Modul tersebut masing-masing memiliki fungsi yang saling berhubungan satu sama lainnya. Modul tersebut adalah modul sistem minimum, modul tampilan berupa LCD, dan modul Sensor PING))) berupa pemancar dan penerima ultrasonik.

Microcontroller sebagai pusat kendali dari sistem ini. Di dalam microcontroller terdapat program yang mengatur data dan mengumpulkan data yang dikirim oleh sensor jarak. Microcontroller mengatur kapan sinyal ultrasonic harus dipancarkan, menghitung nilai waktu dari saat gelombang mulai dipancarkan sampai diterima kembali, memproses data dari sensor ultrasonic kemudian ditampilkan ke LCD, dan memberikan peringatan dini melalui buzzer dan LED. Pengujian sensor ultrasonic dan layar LCD sebagai pemberi informasi telah dilakukan, dan hasilnya sesuai dengan keadaan sesungguhnya.

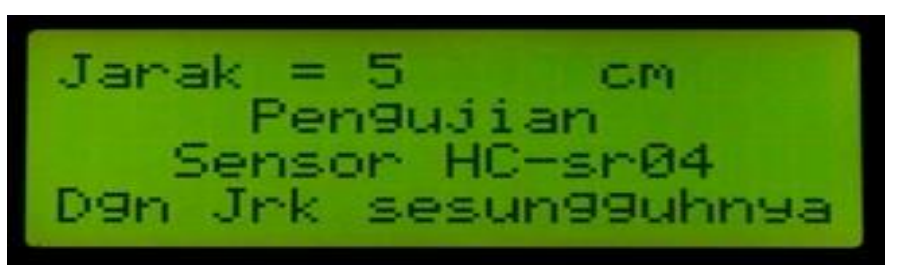

Gambar 9. Pengujian sensor dan LCD

\section{B. Perangkat Lunak}

Perangkat lunak yang digunakan pada sistem terdiri dari dua bagian, yaitu Arduino IDE yang berfungsi untuk merancang program yang akan ditanamkan pada microcontroller agar sistem dapat bekerja dan Processing yang berfungsi untuk merancang program antarmuka monitoring sistem. Kedua perangkat ini dapat diintegrasikan dan terdapat beberapa pustaka yang mempermudah user untuk melakukan pemrograman. 


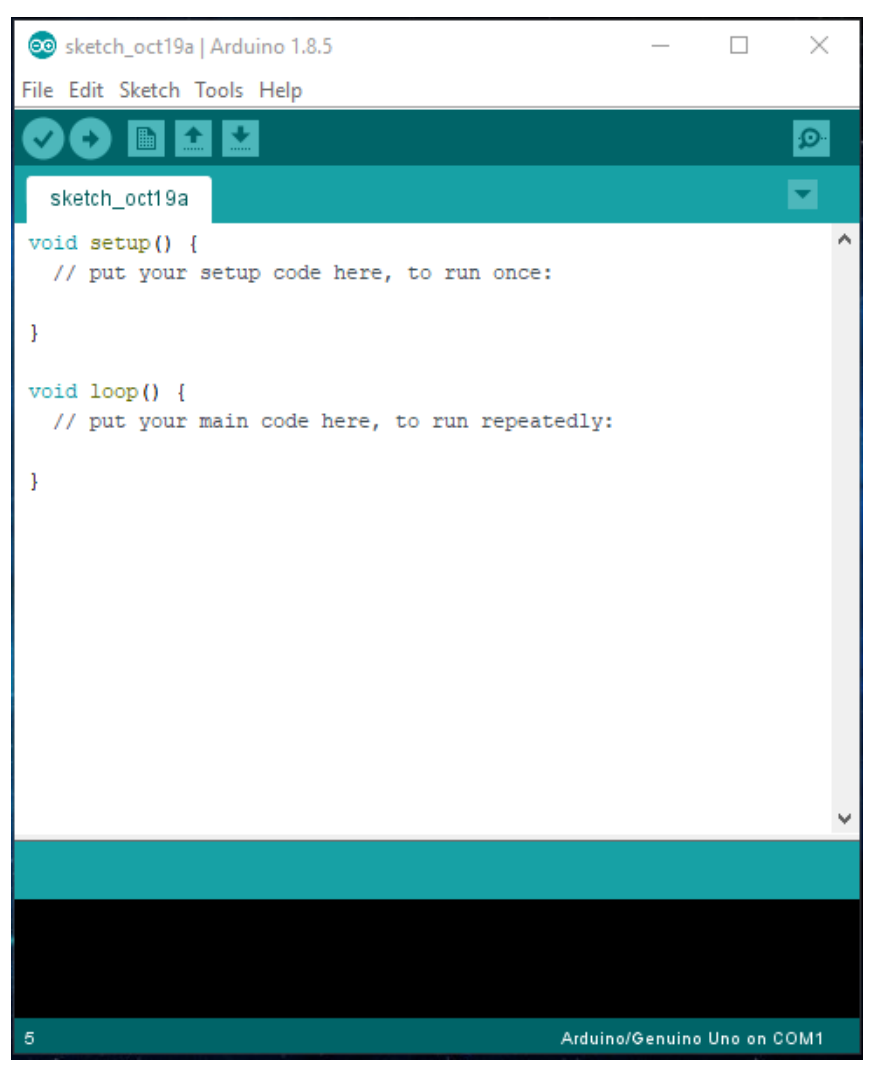

Gambar 10. Tampilan aplikasi Arduino IDE

\section{Pengujian Sistem}

Pengujian sensor ultrasonic dan LED dilakukan dengan cara menggunakan tangan pada jarak tertentu dan sensor akan membaca jarak, lalu informasi akan diberikan kepada microcontroller dan menampilkannya lewat LED. berikut adalah tabel warna LED dan informasi mengenai jarak:

\begin{tabular}{|l|l|}
\hline Led biru & $>=16 \mathrm{~cm}$ \\
\hline Led hijau & $<=15 \mathrm{~cm}$ \\
\hline Led kuning & $<10 \mathrm{~cm}$ \\
\hline Led merah & $<5 \mathrm{~cm}$ \\
\hline
\end{tabular}

Gambar 11. Tabel pengujian jarak 


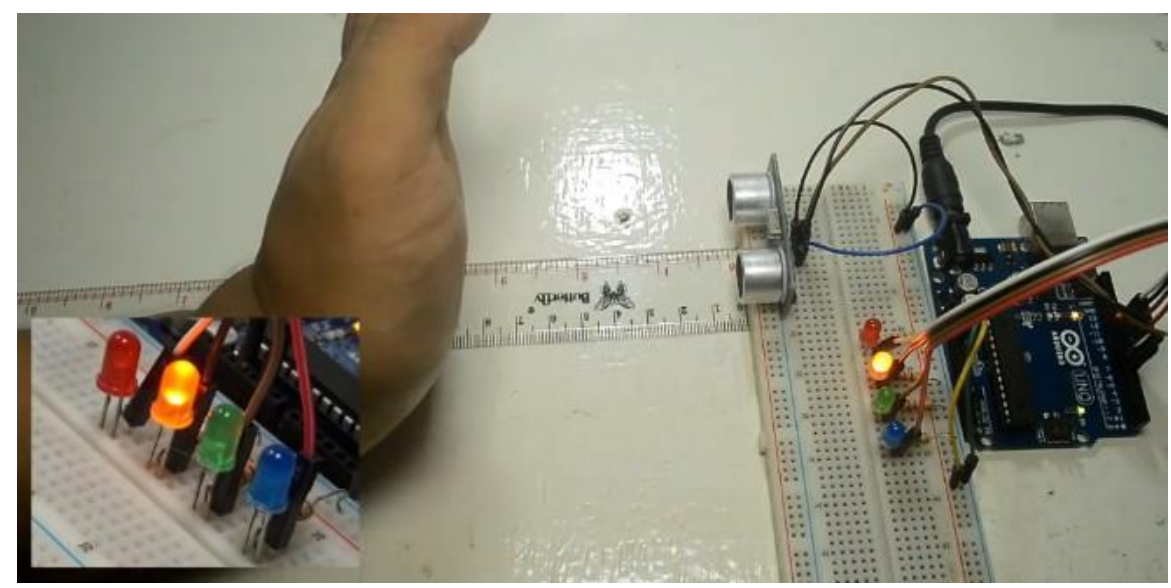

Gambar 12. Pengujian sensor ultrasonic dengan LED

pada percobaan ini sistem sensor berjalan dengan baik sesuai jarak pada aslinya dan sangat akurat. lalu pengujian berikutnya sensor ultrasonic dan LCD dilakukan dengan cara menggunakan tangan pada jarak tertentu dan sensor akan membaca jarak, lalu informasi akan diberikan kepada microcontroller dan menampilkannya pada LCD.

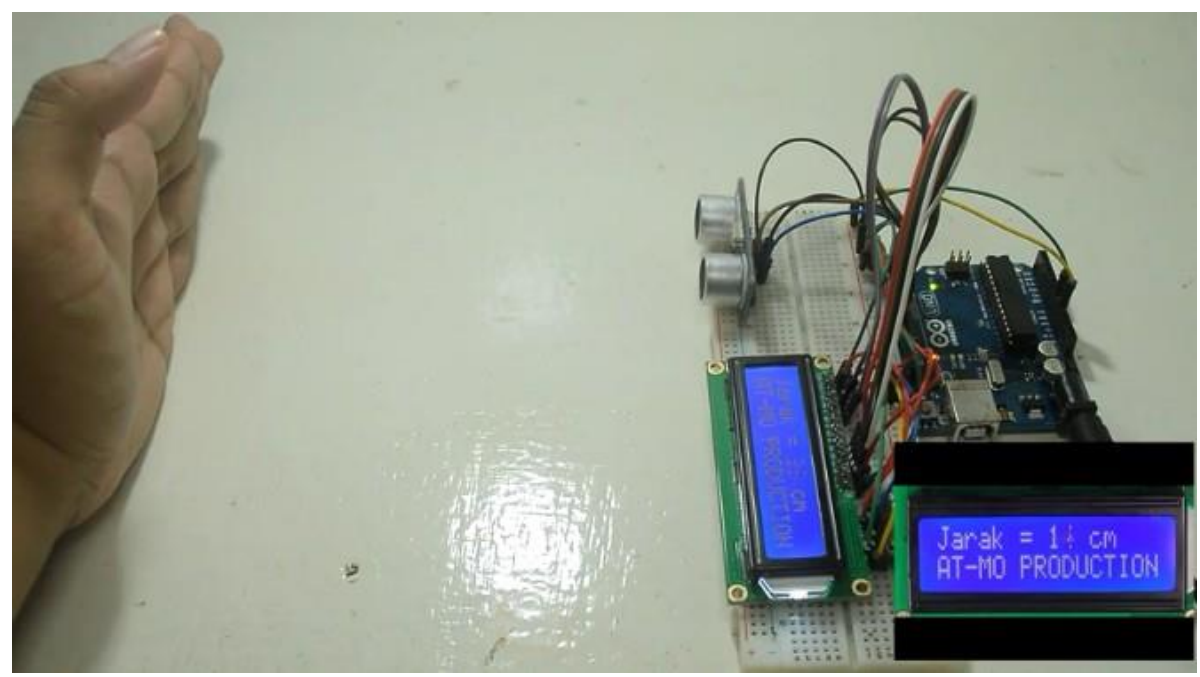

Gambar 13. Pengujian sensor ultrasonic dan LCD

Hasil dari setiap pengujian terbukti berjalan dengan baik dan akurat. dari sistem tersebut telah dirancang dan diimplementasikan tersaji pada Gambar 14. 


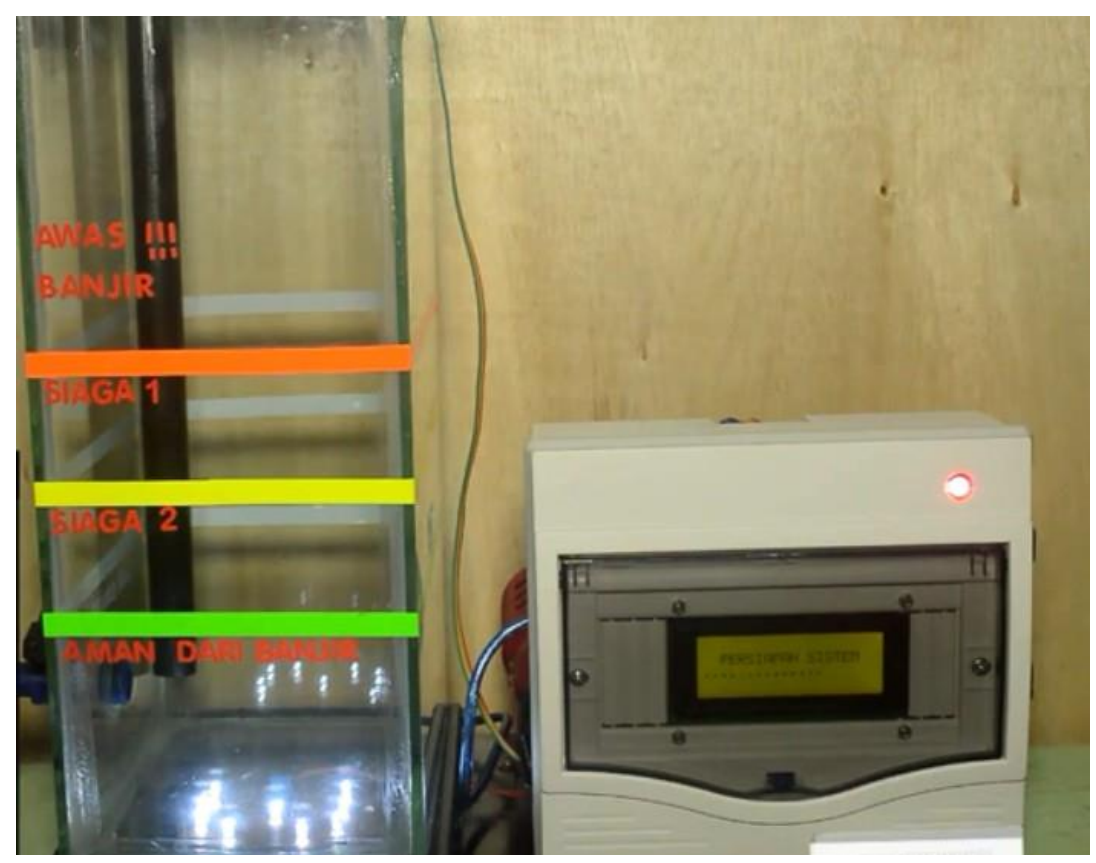

Gambar 14. Rancangan implementasi system

System telah diimplementasikan dan bekerja dengan baik, cara kerja dari system ini adalah di bawah garis hijau adalah titik aman yang dimana program tidak akan memberikan notifikasi apapun kepada user, jika sudah melewati garis hijau maka system akan memberikan notifikasi lewat sms "siaga 2" yang dimana ketinggian air meningkat dan harus waspada. Jika ketinggian air sudah melewati garis berwarna kuning maka system akan memberikan notifikasi lewat sms "siaga 1" yang dimana air sudah diatas rata-rata dan sangat berpotensi terjadinya banjir. Dan Jika ketinggian air sudah melewati garis berwarna merah maka system akan memberikan notifikasi lewat sms "awas banjir" air sudah meluap dan sudah berada di ketinggian yang tidak wajar, sehingga terjadinya banjir.

Notifikasi berupa sms kepada nomor user sangat berpengaruh kepada sinyal dari kartu GSM yang digunakan. Jika GSM yang digunakan memiliki sinyal yang kurang bagus, maka akan terjadi kendala pada saat pengiriman notifikasi sms, dan sangat menghambat user untuk bersiaga. Begitu pula sebaliknya, jika GSM yang digunakan memiliki sinyal yang bagus, maka pesan yang terkirim akan langsung diterima oleh user sesuai dengan kondisi yang ada pada tempat kejadian. Pada pengujian system, saya menggunakan 4 device handphone yang akan dikirimkan notifikasi berupa sms secara bersamaan, dan sistem berjalan dengan baik. Tersaji pada gambar 15 . 


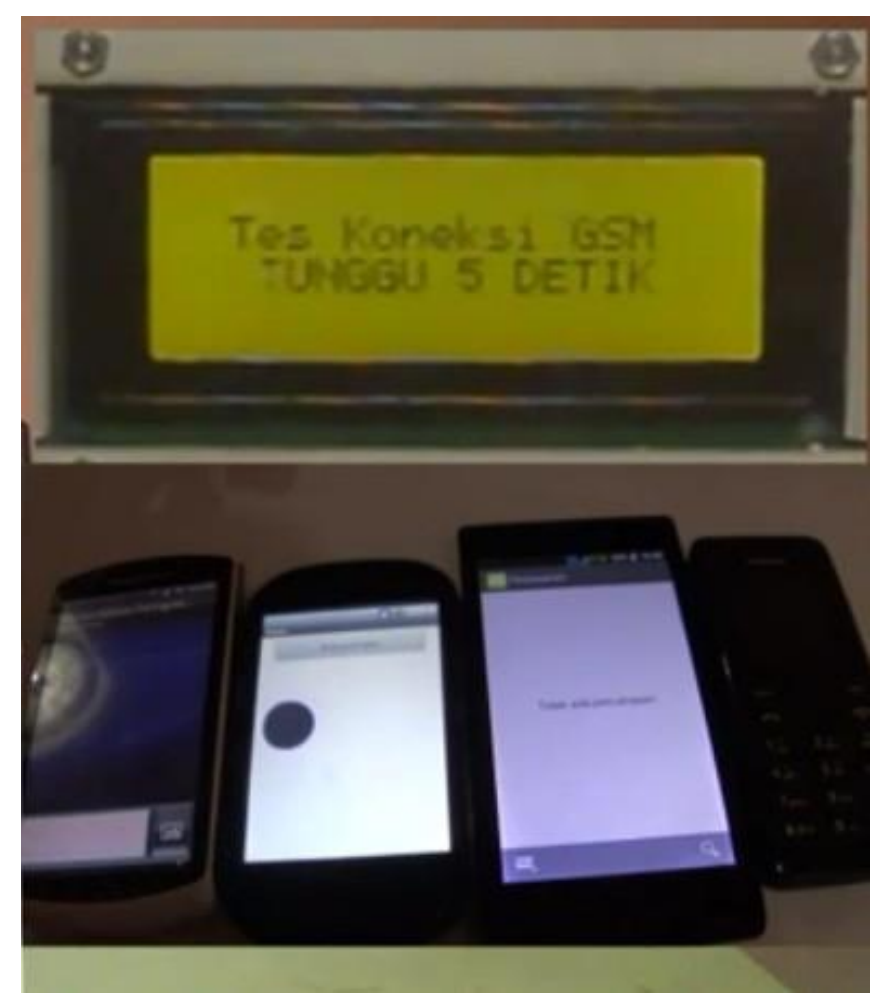

Gambar 15. Pengiriman Notification

\section{KESIMPULAN}

Kesimpulan dari perancangan alat pengukur ketinggian air berbasis arduino uno dan sensor ultrasonic sebagai peringatan dini banjir dengan notification sms adalah hasil pengujian system menunjukkan bahwa sensor ultrasonic yang digunakan mampu mengukur ketinggian air dari 5 $\mathrm{cm}$ sampai $50 \mathrm{~cm}$ dengan hasil yang akurat, dengan rata-rata keakuratannya $98 \%$. Microcontroller juga dapat menangkap data dengan cepat dan langsung dikirimkan ke LCD untuk ditampilkan serta memberikan notifikasi lewat sms sesuai dengan batasan-batasan ketinggian yang sudah diatur. Sehingga implementasi perancangan alat pengukur ketinggian air berbasis arduino uno dan sensor ultrasonic sebagai peringatan dini banjir dengan notification sms berjalan dengan baik.

\section{SARAN}

Dari kesimpulan diatas penulis dapat menyarankan bahwa alat ini dapat diimplementasikan pada daerah yang rawan banjir oleh warga maupun pemerintah daerah tersebut, agar warga sekitar dapat berjaga-jaga pada saat musim penghujan datang ataupun saat air sungai akan meluap dikarenakan banjir kiriman dari daerah yang lain. alat ini sendiri dapat dikembangkan lebih lanjut agar terkoneksi dengan sistem pemantau pada komputer yang dapat memeriksa ketinggian air setiap saat. 


\section{DAFTAR PUSTAKA}

[1] Dwiyatno, S., \& Prabowo, I. (2017). Rancang Bangun Alat Ukur Tinggi Badan Digital Menggunakan Sensor Ultrasonik, 4(1), 15-20.

[2] Susanto, R., Kristanto, Y., Ridwanto, S., \& Hisnuaji, D. (2007). Perancangan Dan Implementasi Sensor Parkir Pada Mobil Menggunakan Sensor Ultrasonik. CommIT, Vol. 1 No. 1 Mei 2007, Hlm. 18-29, 1(1), 18-29.

[3] Lydia Wiharto, H., \& Yuliananda, S. (2016). Penerapan Sensor Ultrasonik Pada Sistem Pengisian Zat Cair Dalam Tabung Silinder Berbasis Mikrokontroler ATmega 16, 01(02), 159-168.

[4] Suhaeb, S. (2016). Desain Tongkat Elektronik Bagi Tunanetra Berbasis Sensor Ultrasonik Dan Mikrokontroller Atmega8535. Jurnal Scientific Pinisi, 2, Nomor 2, 131136.

[5] Budiarso, Z., \& Prihandono, A. (2015). Implementasi Sensor Ultrasonik Untuk Mengukur Panjang Gelombang Suara Berbasis Mikrokontroler, 20(2), 171-177.

[6] Arasada, B., \& Suprianto, B. (2017). Aplikasi Sensor Ultrasonik Untuk Deteksi Posisi Jarak Pada Ruang Menggunakan Arduino Uno. Jurnal Teknik Elektro, 6(2), 137-145. 